\title{
Short-burst oxygen therapy for COPD patients: a 6-month randomised, controlled study
}

\author{
T. Eaton*, W. Fergusson*, J. Kolbe ${ }^{\#}$, C.A. Lewis* and T. West*
}

ABSTRACT: Short-burst oxygen therapy (SBOT) remains widely advocated for patients with chronic obstructive pulmonary disease (COPD), despite a lack of supporting evidence. The aim of this randomised, double-blind, placebo-controlled, parallel group study was to determine whether SBOT improves health-related quality of life (HRQL) or reduces acute healthcare utilisation in patients discharged following an acute exacerbation of COPD.

Consecutive patients were screened; 78 of 331 were eligible for randomisation to cylinder oxygen, cylinder air or usual care following discharge. Patients were elderly with high acute healthcare utilisation, forced expiratory volume in one second of $<1 \mathrm{~L}$ and had dyspnoea limiting daily activity but were not hypoxaemic at rest. Over the 6-month study period, there were no significant differences between patient groups in HRQL (Chronic Respiratory Questionnaire (CRQ), 36-item Short-Form Health Survey, Hospital Anxiety and Depression Scale) except for CRQ emotion domain. There were no significant differences in acute healthcare utilisation. Time to readmission was greatest in the usual care group. Cylinder use was high initially, but rapidly fell to very low levels within weeks in both cylinder oxygen and air groups.

In conclusion, the availability of short-burst oxygen therapy for chronic obstructive pulmonary disease patients discharged from hospital following an acute exacerbation did not improve health-related quality of life or reduce acute healthcare utilisation. These results provide no support for the widespread use of short-burst oxygen therapy.

KEYWORDS: Acute healthcare utilisation, chronic obstructive pulmonary disease, health-related quality of life, randomised controlled, short-burst oxygen therapy

hort-burst oxygen therapy (SBOT) is defined as the "intermittent use of oxygen for the relief of breathlessness, before exercise or for recovery after exercise" [1]. There is no evidence from acute studies that SBOT provides clinically meaningful benefit for patients with chronic obstructive pulmonary disease (COPD) [2-4]. Despite this, the use of SBOT appears to be common practice for distressed dyspnoeic COPD patients $[1,5]$. This has considerable financial implications. In the UK, cylinder prescriptions almost doubled in the last decade with annual costs $>£ 10$ million [6].

COPD is a leading cause of morbidity and mortality in many countries, including $\mathrm{New}$ Zealand, where it is the fourth most common cause of hospital admission [7]. Readmission rates are high. A comprehensive study from the USA of patient outcomes following an exacerbation reported $50 \%$ of patients were readmitted within 6 months [8]. A recent large international survey conducted in Canada and the USA, and Europe emphasised the high economic impact of COPD with the majority of healthcare costs accounted for by hospitalisations [9].

Over half the referrals to the present authors' oxygen service originate from COPD patients following a recent admission [10]. These patients often do not fulfil criteria for other modes of oxygen prescription, such as long-term or ambulatory oxygen, where a more secure evidencebase exists [11-13]. A report from the Royal College of Physicians observed that "despite extensive prescription of SBOT, there is no adequate evidence available for firm recommendations and further research is required" [1]. This is an important patient group, not only in terms of high consumption of scarce healthcare resource, but also with regard to personal burden of chronic disease with distressing levels of dyspnoea and poor health-related quality of life (HRQL), which declines inexorably over time [8,
AFFILIATIONS

*Respiratory Services, Auckland City Hospital, and

\# Dept of Medicine, Faculty of Health Sciences, University of Auckland, Auckland, New Zealand.

CORRESPONDENCE

T. Eaton

Respiratory Services

Auckland City Hospital

Auckland 1

New Zealand

Fax:6496310712

E-mail: teaton@adhb.govt.nz

Received:

August 222005

Accepted after revision:

December 062005 
14-17]. The original landmark clinical oxygen studies [11, 12] concentrated on survival as the primary outcome. The significance of other measures, including symptom relief, HRQL and acute healthcare utilisation, is now better appreciated. There are no previous randomised long-term studies of domiciliary SBOT in COPD patients and no studies have specifically addressed the impact of SBOT on either HRQL or acute healthcare utilisation.

The aim of this study was to determine whether the availability of SBOT to dyspnoeic but not hypoxic COPD patients following hospital discharge from an acute exacerbation improves HRQL and reduces acute healthcare utilisation.

\section{METHODS}

A 6-month prospective, randomised, double-blind, placebocontrolled, parallel group study of cylinder oxygen versus cylinder air versus usual care was performed. Patient recruitment and study design are outlined in figure 1. Consecutive patients admitted to (Auckland and Green Lane Hospitals, Auckland, New Zealand) between November 2001 and December 2003 with an acute exacerbation of COPD were recruited.

\section{Inclusion criteria}

The inclusion criteria were as follows: 1) Hospital in-patients with an acute exacerbation of COPD; 2) moderate or severe COPD, as defined by British Thoracic Society criteria [18]; 3) exertional dyspnoea interfering with daily activity; 4) resting arterial oxygen tension $>8 \mathrm{kPa}$ on air at discharge (i.e. would not fulfil criteria for long-term oxygen therapy (LTOT)) [18]; and 5) ability to complete HRQL questionnaires.

\section{Exclusion criteria}

The exclusion criteria were as follows: 1) Current smoker; 2) severe comorbidity, e.g. malignancy, likely to cause death within the 6-month study period; 3) resident of a long-term facility in which SBOT is available; 4) hypercapnia (resting carbon dioxide arterial pressure $>6.0 \mathrm{kPa}$ ) (based on possible risk of loss of hypoxic drive with supplemental oxygen).

Local Ethics Committee approval was obtained and all patients signed written informed consent.

Patients were randomised using computer-generated randomisation numbers to one of the following groups: 1) Cylinder oxygen; 2) cylinder air; and 3) usual care. Patients attended for visit one within a week of discharge, visit two at 2 months and visit three at 6 months. All patients received usual care from their usual healthcare providers.

\section{Domiciliary short-burst cylinder oxygen/air}

Patients randomised to either cylinder oxygen or air received comprehensive practical and written education in the care and usage of their cylinder gas (CIG/Luxfer, NZ gas code no. 180, AS177777, D Content (L) 1,640, maximum fill pressure 16.6 $\mathrm{mPa}$ ) (Appendix 1). To ensure double-blinding, cylinders, prefilled with air or oxygen, were identifiable only by a unique cylinder number. Cylinders were painted pink to ensure they would not be used in routine clinical care. Allocation of cylinders was by a separate member of the research team not involved in patient assessment. Safety issues were addressed as outlined in Appendix 1 and approved by New Zealand Occupational Safety and Health (Wellington, New Zealand).

\section{Instructions to patients}

Patients were given standardised instructions. They were to use their cylinder gas at $2 \mathrm{~L} \cdot \mathrm{min}^{-1}$ via nasal prongs, as necessary for distressing or limiting breathlessness. Selfreported cylinder use was recorded in patient diaries.

\section{Baseline measures}

Patient demographies were recorded. Social support was measured by a modification of the scale of O'REILLY et al. [19], which has been successfully used in asthma [20] and COPD patients [21]. General social support was assessed by asking whether they had someone to confide in or discuss matters with when they had to make an important decision, were worried about a personal matter, or were going through a difficult time. Disease-specific support was assessed by asking whether there was anyone to help them with their breathing problems, aside from their usual healthcare providers. Patients were asked how satisfied they were with the support received.

\section{Physiological measures}

Forced expiratory volume in one second (FEV1) and forced vital capacity were measured (R-Model Vitalograph Ltd, Maids Moreton, UK) at all visits to American Thoracic Society standards [22] and expressed as percentage predicted (European Community Coal and Steel prediction equations) [23]. Arterial blood gases on air were measured at rest breathing room air for at least $20 \mathrm{~min}$. Cutaneous oximetry (Nellcor N-20PAi Puritan Bennett Inc., Pleasanton, CA, USA) was obtained using a finger probe.

\section{Health-related quality of life questionnaires}

Chronic respiratory questionnaire

The chronic respiratory questionnaire (CRQ) is a well validated, repeatable and responsive disease-specific, intervieweradministered instrument with four domains, namely, dyspnoea, fatigue, emotional function and mastery [24]. Each answer is scored from 1-7 ( $7=$ optimal). The minimum clinically significant difference is a change of at least 2.5 in dyspnoea, 2 in fatigue, 3.5 in emotional function and 2 in mastery [25].

\section{Medical Outcomes Study 36-item Short-Form Health Survey} The Medical Outcomes Study 36-item Short-Form Health Survey (SF-36) is a well validated, responsive, generic, multiitem HRQL tool which yields an eight-dimensional profile, each scale having a range from 0-100 (100=optimal) [26].

\section{Hospital anxiety and depression scale}

The hospital anxiety and depression (HAD) scale is a reliable self-assessment scale used for evaluating anxiety and depression in the physically ill, and consists of 14 items, seven of which score for anxiety and seven for depression, each with a range from $0-21(0=$ optimal $)$ [27].

\section{Acute healthcare utilisation}

Acute healthcare utilisation was assessed by number of COPDrelated readmissions and unscheduled emergency visits (emergency departments/primary care). Time to first COPD-related 


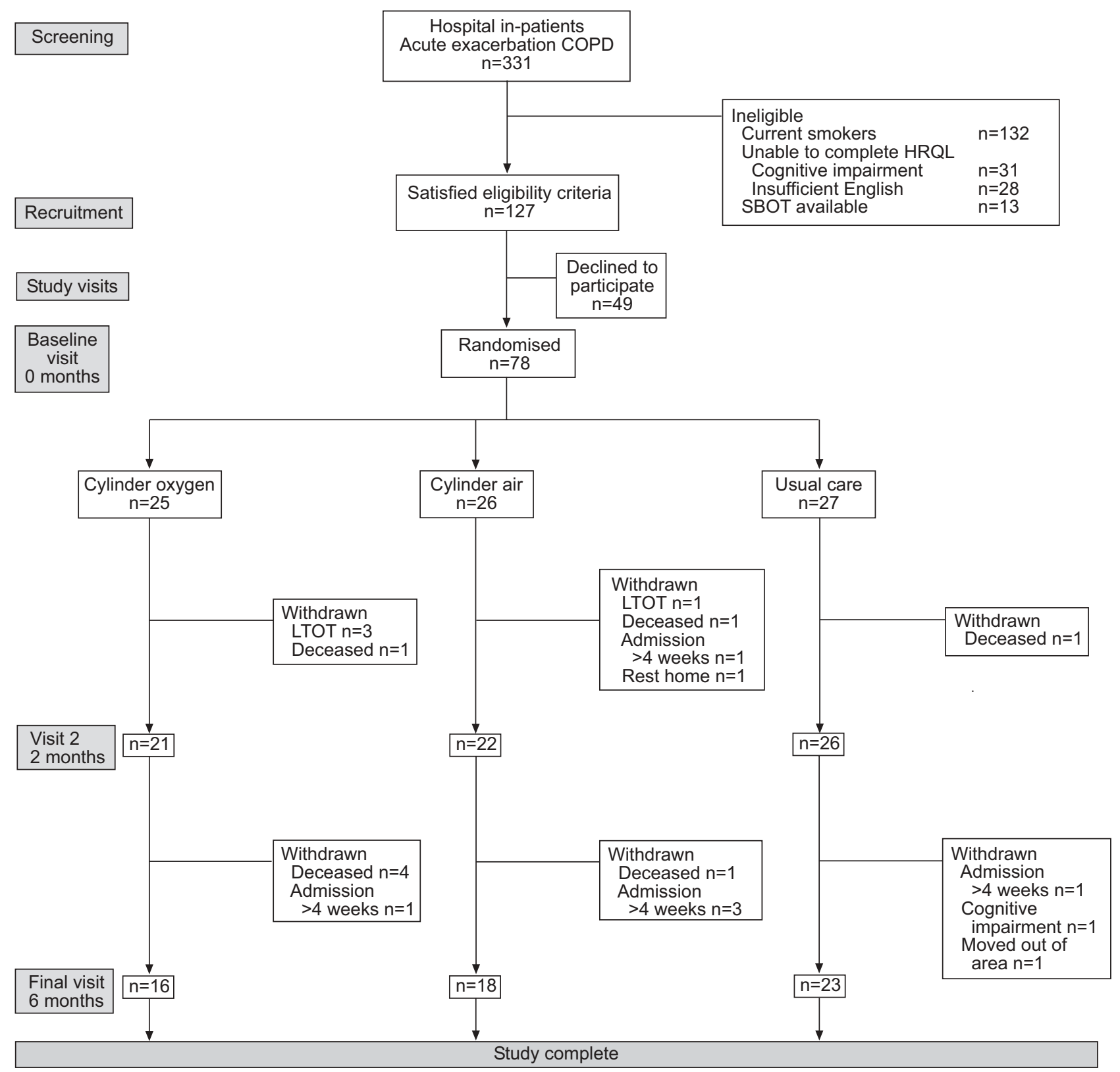

FIGURE 1. Study design and patient recruitment. COPD: chronic obstructive pulmonary disease; $\mathrm{HRQ}$ : health-related quality of life; SBOT: short-burst oxygen therapy; LTOT: long-term oxygen therapy.

readmission was determined. Data were obtained from patient diaries and confirmed with hospital and primary healthcare records.

\section{Statistical analysis}

Differences across groups were compared using one-way ANOVA. Linear mixed models were used to compare HRQL in the cylinder oxygen, cylinder air and usual care groups [28]. Baseline measures were included as outcome data and time was fitted as fixed. The average rate of change was assessed by fitting a treatment and time interaction term. Results are reported as point estimates for average change in each treatment group with $95 \%$ confidence interval. A p-value $<0.05$ was considered statistically significant.

\section{RESULTS}

\section{Patient characteristics}

A total of 331 consecutive in-patients (with an acute exacerbation of COPD) were screened; 204 were ineligible, the majority due to current smoking status (fig. 1). Of the 127 patients who satisfied eligibility criteria, 49 declined to participate and 78 were available for randomisation. Baseline characteristics are detailed in table 1 . Patients were elderly (mean age $77 \mathrm{yrs}$ ), with a mean FEV1 $<1$ L. They had high COPD-related morbidity in terms of acute healthcare utilisation. They also had a high rate of significant comorbidity: 19 $(76 \%), 17(65 \%)$ and $20(74 \%)$ of the cylinder oxygen, cylinder air and usual care group, respectively, had at least one serious comorbidity. The majority of patients $(>90 \%)$ stated that they had someone to confide in and that they were very or 
TABLE 1 Baseline patient characteristics

\begin{tabular}{|c|c|c|c|}
\hline Patients n & 25 & 26 & 27 \\
\hline Male & $14(56)$ & $13(50)$ & $9(33)$ \\
\hline European & $20(80)$ & $24(92)$ & $25(93)$ \\
\hline Smoking history pack-yrs & $38.4 \pm 21.6$ & $35.1 \pm 22.5$ & $38.2 \pm 20.26$ \\
\hline Resting $\mathrm{Pa}_{\mathrm{a}} \mathrm{O}_{2}$ on air $\mathrm{kPa}$ & $9.6 \pm 1.29$ & $10.1 \pm 1.69$ & $10.3 \pm 1.63$ \\
\hline Resting $\mathrm{Pa}, \mathrm{CO}_{2}$ on air $\mathrm{kPa}$ & $5.3 \pm 0.62$ & $5.4 \pm 0.43$ & $5.1 \pm 0.58$ \\
\hline Resting $\mathrm{Sa}_{\mathrm{a}, \mathrm{O}_{2}}$ on air \% & $94.6 \pm 1.93$ & $94.7 \pm 1.56$ & $95.6 \pm 1.92$ \\
\hline Urgent visits to GP during last 6 of 12 months & $1.0 \pm 1.95$ & $2.1 \pm 2.78$ & $0.9 \pm 0.86$ \\
\hline Hospital admission last 6 of 12 months ${ }^{\#}$ & $2.2 \pm 2.36$ & $1.8 \pm 1.47$ & $1.4 \pm 0.97$ \\
\hline Help with breathing problem (disease-specific) & $4(16)$ & $3(12)$ & $4(15)$ \\
\hline
\end{tabular}

Data are presented as mean \pm SD or $n(\%)$, unless otherwise indicated. $F E V_{1}$ : forced expiratory value in one second; \% pred: percentage of predicted value; $\mathrm{Pa}_{1} \mathrm{O}_{2}$ : arterial oxygen tension; $\mathrm{Pa}_{\mathrm{a}} \mathrm{CO}_{2}$ : arterial carbon dioxide tension; $\mathrm{Sa}, \mathrm{O}_{2}$ : arterial oxygen saturation; GP: general practitioner. \#: hospital admissions in the last 6 of 12 months excluding sentinel admission; ${ }^{\top}: p=0.04$.

TABLE 2 Baseline health-related quality of life (HRQL)

Cylinder oxygen Cylinder air Usual care p-value

\begin{tabular}{lcccc}
$\begin{array}{l}\text { Patients n } \\
\text { CRQ }\end{array}$ & 25 & 26 & 27 & \\
$\quad$ Dyspnoea & $17.8 \pm 5.0$ & $17.5 \pm 4.2$ & $16.1 \pm 4.4$ & 0.323 \\
Fatigue & $14.6 \pm 5.8$ & $12.4 \pm 3.9$ & $12.4 \pm 3.4$ & 0.133 \\
Emotional function & $33.0 \pm 9.7$ & $30.6 \pm 7.8$ & $28.7 \pm 6.7$ & 0.168 \\
Mastery & $17.4 \pm 4.8$ & $16.5 \pm 4.7$ & $16.1 \pm 4.4$ & 0.575 \\
$\quad$ Total & $82.9 \pm 21.8$ & $77.0 \pm 16.3$ & $73.3 \pm 14.3$ & 0.151 \\
SF-36 & & & & \\
Physical & $25.4 \pm 18.7$ & $21.9 \pm 16.9$ & $22.2 \pm 15.8$ & 0.725 \\
Role physical & $17.0 \pm 33.6$ & $4.8 \pm 12.3$ & $6.5 \pm 13.1$ & 0.102 \\
Bodily pain & $74.1 \pm 31.9$ & $67.1 \pm 29.5$ & $63.6 \pm 32.0$ & 0.470 \\
General health & $48.5 \pm 23.6$ & $39.3 \pm 21.3$ & $48.7 \pm 21.5$ & 0.225 \\
$\quad$ Vitality & $44.8 \pm 24.3$ & $41.5 \pm 22.8$ & $42.4 \pm 16.4$ & 0.853 \\
Social functioning & $60.5 \pm 33.0$ & $56.3 \pm 31.3$ & $50.9 \pm 26.4$ & 0.515 \\
Role emotional & $48.0 \pm 46.2$ & $48.0 \pm 42.0$ & $43.2 \pm 42.2$ & 0.899 \\
$\quad$ Mental health & $77.0 \pm 17.6$ & $68.9 \pm 19.7$ & $69.2 \pm 19.0$ & 0.229 \\
SF-36 summary & & & & \\
scores & & & & \\
Mental & $30.4 \pm 8.9$ & $27.2 \pm 7.2$ & $28.73 \pm 7.3$ & 0.664 \\
$\quad$ Physical & $47.2 \pm 13.9$ & $45.1 \pm 13.2$ & $43.8 \pm 12.5$ & 0.368 \\
HAD & & & & \\
Anxiety & $5.3 \pm 4.0$ & $5.6 \pm 3.2$ & $7.3 \pm 4.2$ & 0.140 \\
Depression & $4.2 \pm 4.1$ & $5.1 \pm 4.0$ & $4.7 \pm 3.0$ & 0.653 \\
\hline & & & &
\end{tabular}

Data are presented as mean $\pm \mathrm{SD}$, unless otherwise indicated. $\mathrm{CRQ}$ : chronic respiratory questionnaire; SF-36: Medical Outcomes Study 36-item Short-Form Health Survey; HAD: hospital anxiety and depression. ${ }^{*}$ : higher scores in $\mathrm{CRQ}$ and SF-36 indicate better HRQL; ": higher scores in HAD indicate worse emotional function. extremely satisfied with this support. However, very few patients $(<15 \%)$ felt they had someone to specifically help them with their breathing. Patient groups were well matched, with no significant differences except that more patients in the usual care group lived alone $(\mathrm{p}=0.04)$.

Baseline HRQL measured by the disease-specific CRQ, generic SF-36 and HAD is detailed in table 2. No significant differences were observed between patient groups. Patients were importantly dyspnoeic, as reflected by the CRQ dyspnoea domain.

\section{Primary outcome measures}

Changes in health-related quality of life

There were no significant differences between patient groups in any of the HRQL measures (CRQ, SF-36, HAD) over 6month study period, except for the CRQ emotion domain. This only just reached statistical significance, with the greatest improvement occurring in the usual care group (table 3 ). There were no significant differences in the emotional and mental health domains of the SF-36 or HAD. Patients remained importantly dyspnoeic, as reflected by the CRQ dyspnoea domain, with no significant improvement over the 6-month study period.

Acute healthcare utilisation over 6-month study period Acute healthcare utilisation and, in particular, hospital readmission was high. However, there were no significant differences in number of readmissions or unscheduled visits between patient groups over the study period, although there was a trend towards fewer events in the usual care group (table 4). Furthermore, time to first readmission was significantly greater $(p=0.012)$ for the usual care group (figure 2$)$.

The pattern of cylinder use over time is displayed in figure 3. Median cylinder use was high initially but fell rapidly within 


\begin{tabular}{|c|c|c|c|c|}
\hline \multirow[t]{3}{*}{ TABLE 3} & \multicolumn{4}{|c|}{ Changes in health-related quality of life ${ }^{\#}$} \\
\hline & \multicolumn{3}{|c|}{$\begin{array}{l}\text { Average change } \text { month }^{-1} 95 \% \\
\text { confidence interval }\end{array}$} & \multirow{2}{*}{ p-value } \\
\hline & Cylinder oxygen & Cylinder air & Usual care & \\
\hline \multicolumn{5}{|l|}{ CRQ } \\
\hline Dyspnoea & $0.9(-0.5-2.3)$ & $-0.6(-1.9-0.8)$ & $1.0(-0.2-2.2)$ & 0.171 \\
\hline Fatigue & $0.4(-0.6-1.5)$ & $0.3(-0.7-1.4)$ & $0.8(-0.1-1.8)$ & 0.763 \\
\hline Emotional function & $0.7(-0.8-2.2)$ & $-0.4(-1.8-1.1)$ & $2.1(0.8-1.8)$ & 0.045 \\
\hline Mastery & $1.2(0.1-2.3)$ & $0.7(-0.4-1.7)$ & $1.0(0.02-1.9)$ & 0.797 \\
\hline Total & $3.1(-1.3-7.5)$ & $0.01(-4.2-4.2)$ & $5.0(1.2-8.8)$ & 0.219 \\
\hline \multicolumn{5}{|l|}{ SF-36 } \\
\hline Physical & $-0.4(-3.9-3.0)$ & $-0.8(-4.1-2.5)$ & $2.9(-0.1-5.8)$ & 0.185 \\
\hline Role physical & $1.8(-6.8-10.3)$ & $13.4(5.2-21.6)$ & $8.7(1.3-16.1)$ & 0.152 \\
\hline Bodily pain & $-3.6(-10.6-3.3)$ & $-1.9(-8.6-4.8)$ & $0.5(-5.6-6.6)$ & 0.667 \\
\hline General health & $-2.8(-7.1-1.5)$ & $-1.7(-5.8-2.3)$ & $-1.5(-5.2-2.1)$ & 0.891 \\
\hline Vitality & $2.7(-1.9-7.3)$ & $1.4(-3.1-5.9)$ & $3.1(-0.9-7.1)$ & 0.840 \\
\hline Social functioning & $1.4(-7.2-9.9)$ & $2.1(-6.1-10.4)$ & $3.7(-7.2-14.5)$ & 0.233 \\
\hline Role emotional & $7.1(-5.3-19.4)$ & $4.4(-7.6-16.4)$ & $10.0(2.5-17.6)$ & 0.914 \\
\hline Mental Health & $2.1(-1.7-5.8)$ & $1.8(-1.8-5.5)$ & $0.9(-2.3-4.1)$ & 0.874 \\
\hline \multicolumn{5}{|l|}{$\begin{array}{l}\text { SF-36 summary } \\
\text { scores }\end{array}$} \\
\hline Mental & $2.5(-0.8-5.8)$ & $0.8(-2.3-4.0)$ & $1.9(-0.8-4.7)$ & 0.745 \\
\hline Physical & $-1.3(-3.0-0.4)$ & $0.6(-1.0-2.2)$ & $0.9(-0.5-2.4)$ & 0.119 \\
\hline \multicolumn{5}{|l|}{ HAD } \\
\hline Anxiety & $0.03(-0.8-0.8)$ & $-0.1(-0.8-0.7)$ & $-0.3(-1.0-0.4)$ & 0.773 \\
\hline Depression & $0.4(-0.6-0.7)$ & $-0.4(-1.0-0.2)$ & $-0.4(-0.9-0.2)$ & 0.508 \\
\hline
\end{tabular}

Data are presented as $n$ (95\% confidence interval), unless otherwise indicated. CRQ: chronic respiratory questionnaire; SF-36: Medical Outcomes Study 36item Short-Form Health Survey; HAD: hospital anxiety and depression. ${ }^{\# \text { : }}$ reported as average change per month over study period.

weeks in both cylinder oxygen and air groups. Mortality was high in all patient groups with no significant differences in either overall (table 4$)$ or time to death $(p=0.266)$.

\section{DISCUSSION}

This is the first randomised, double-blind, placebo-controlled, parallel group home-based study of SBOT for COPD patients recently discharged from hospital following an acute exacerbation. The availability of SBOT neither improved HRQL nor reduced acute healthcare utilisation.

SBOT continues to be widely prescribed $[1,5,6]$, despite a number of acute studies that provide little evidence of

TABLE 4 Acute healthcare utilisation over study period

\begin{tabular}{lcccc} 
& Oxygen & Air & Usual care & p-value \\
\hline Patients n & 25 & 26 & 27 & \\
Unscheduled visits & $2(8)$ & $4(15)$ & $5(19)$ & 0.538 \\
Hospital readmission & $18(72)$ & $19(73)$ & $12(44)$ & 0.050 \\
Deaths & $10(40)$ & $4(15)$ & $9(33)$ & 0.135 \\
\hline \multicolumn{5}{l}{} \\
Data are presented as $\mathrm{n}(\%)$, unless otherwise indicated.
\end{tabular}

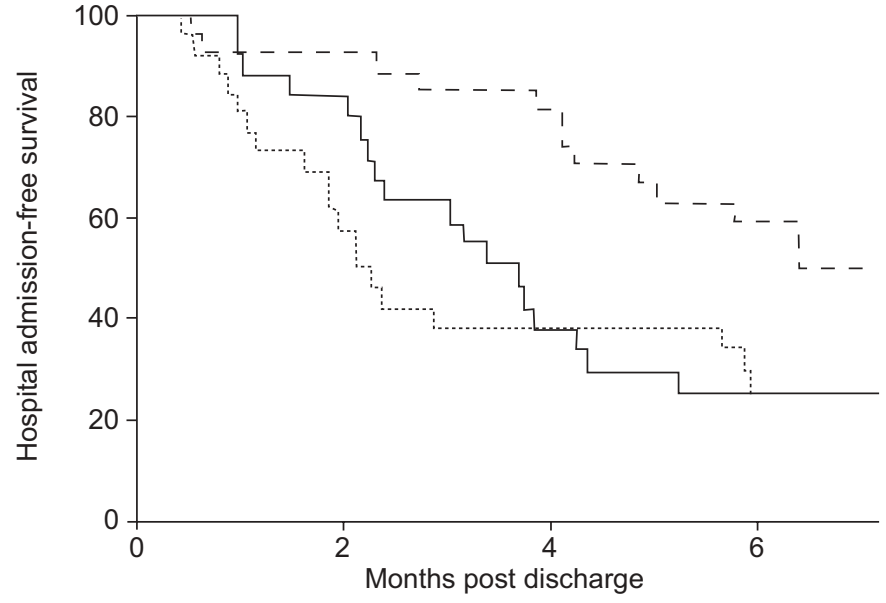

FIGURE 2. Time to first readmission. ——: oxygen; ….... air; - - -: usual care.

meaningful clinical benefit [2-4]. In an evaluation of SBOT pre- and post-exercise in COPD patients, SBOT neither reduced dyspnoea nor improved performance [3], consistent with the results of NANDI et al. [4]. Furthermore, the reproducibility of any response is poor [3, 29]. Oxygen provided to COPD patients during recovery from maximal symptom-limited exercise had no effect on either dyspnoea or recovery time [2]. In this present study, these findings were extended to demonstrate that the longer-term availability of SBOT did not improve HRQL or reduce acute healthcare utilisation.

One of this study's strengths is that it reflects the real-life prescription and use of SBOT in the domiciliary setting, as opposed to the more proscriptive instructions enforced in the acute gym-based studies. Furthermore, the acute SBOT studies did not necessarily recruit the patient group for which SBOT is prescribed in clinical practice [2-4] and the mode(s) of exercise employed was (were) not clinically relevant [2-4]. A recent study concluded that "evidence-based treatment decisions for obstructive lung disease are based on studies which include a very small highly selected fraction of this patient population"

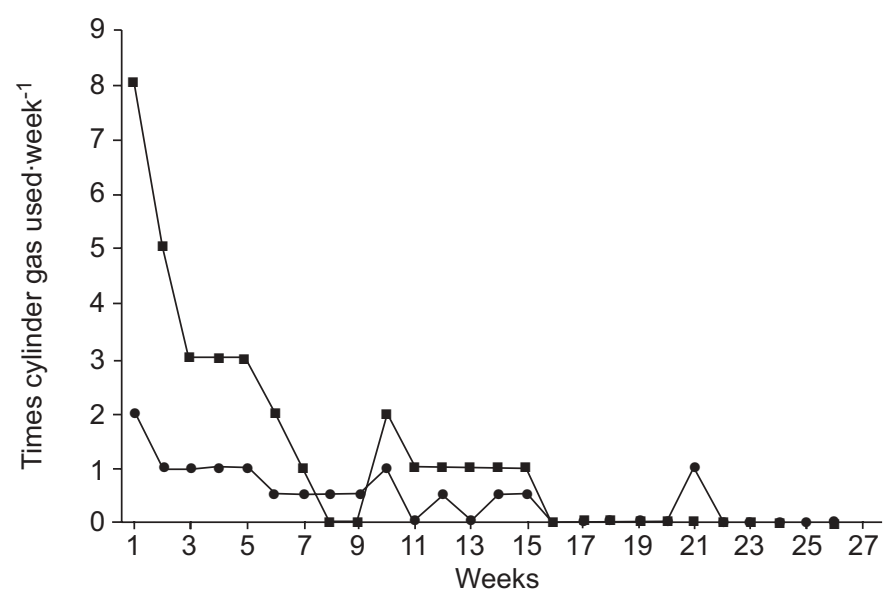

FIGURE 3. Pattern of cylinder use over 6-month study period. oxygen; 
and "it is questionable whether such data scan be extrapolated to a larger, real life population of patients with obstructive lung disease [30]."

The present authors believe that their patients more accurately reflect the population currently prescribed domiciliary SBOT. Hence, the results reported herein are likely to be more generalisable. The present study population was elderly (mean age $77 \mathrm{yrs}$ ), often frail and vulnerable, and with chronic severe disease associated with distressing dyspnoea, poor HRQL and considerable comorbidities. It is salutary that their HRQL was comparable with previously reported HRQL of COPD patients fulfilling the criteria for LTOT [17] and rather worse than COPD patients not fulfilling the criteria for LTOT but suitable for ambulatory oxygen [13]. Acute healthcare utilisation was high; these patients had just required admission for an acute exacerbation of COPD and the majority another admission in the preceding 6 months.

Study of COPD patients following an acute exacerbation was deliberate, recognising that, not only do they represent the majority of referrals to the present authors' oxygen service [10], but also that this is the group for whom any impact on HRQL and acute healthcare utilisation might be expected to be greatest. Further study is required to definitively address domiciliary SBOT in a chronic stable population. Nonetheless, the present study population, by definition, had important dyspnoea limiting daily activity, as reflected by the CRQ dyspnoea domain both at baseline and 6 months. Accordingly, given the present results in conjunction with the largely negative results of the acute gym-based studies, similar results would be expected.

There are considerable practical difficulties in conducting such a study. The baseline patient characteristics bear testament to some of the potential difficulties. These factors were likely to be influential in the comparatively high rate $(39 \%)$ of eligible patients declining to participate. Although patients were excluded only where strictly necessary; nevertheless, 204 $(62 \%)$ proved ineligible, largely due to current smoking or inability to complete HRQL questionnaires. Mortality $(10 \%)$ over the 6-month study period was high. Such patients represent a challenge both to recruit and maintain in clinical studies.

The negative impact of COPD on HRQL is substantial [8, 14-17]. Management should be concentrated on symptom relief and improving HRQL. Modest, but clinically meaningful, improvement in HRQL for COPD patients following the introduction of LTOT [17] is reported. Modest improvements in HRQL have also been shown for COPD patients provided with a domiciliary supply of ambulatory oxygen [13]. However, in this present study of SBOT, there were no significant differences between patient groups in any of the HRQL measures (CRQ, SF-36, HAD), apart from improvement in the $\mathrm{CRQ}$ emotion domain in the usual care group.

It must be emphasised that the present study design was pragmatic and intended to reflect the real-life clinical prescription of SBOT, as outlined in the Royal College of Physicians Report [1], i.e. availability and use as required. The present authors recognise that patients recovering from an acute exacerbation would be expected to improve in time with some effect on usage. This only serves to emphasise the importance of a randomised controlled design such as this, which allowed us to demonstrate that there was no significant difference over time between cylinder oxygen, cylinder air and usual care groups. However, notwithstanding this, the present study population continued with important dyspnoea, as reflected by the CRQ domain at 6 months. Thus, it seems improbable that a therapeutic effect was missed. Any benefit would be perceived promptly, providing immediate positive feedback such that, on the next occasion, the patient would again use the cylinder, resulting in a sustained pattern of use. Whilst acknowledging the limitations of patient diaries, the striking decay in use after an initial burst lends confidence that patients did not perceive sufficient clinical benefit to warrant continued use. It was felt that 6 months would be sufficient to prove a clinically meaningful benefit. Given the results reported herein, it is clear that a longer or indeed larger study would have been futile. The low-level use of SBOT could conceivably have contributed to a failure to show benefit from SBOT; however, analysis of results was on the basis of "intention-to-treat" and such an analysis failed to show clinical benefit. Furthermore, there was no evidence of benefit in terms of HRQL at 2 months, i.e. during a period of relatively higher use of cylinder gas. In line with the present findings, a review of domiciliary cylinder use in the UK also reported low use [5].

The failure to show a HRQL benefit does not exclude a potential separate benefit from SBOT, e.g. the concept of a security blanket, where the presence of a cylinder might be influential in an acute episode. The present study did not support this hypothesis, in that the usual care group performed best with a significantly longer time to first admission and trend towards less acute unscheduled events than the cylinder groups. The patient groups were very well matched, not only for demography, physiological measures and HRQL, but also for potential social confounders. The exception was that more of the usual group lived alone, but this only just reached statistical significance and should not be overemphasised. It is recognised, however, that patients who live alone may be less likely to be readmitted than those with a spouse, who may call emergency services. Using validated measures of social supports [19-21], it was found that patients virtually universally reported that they were very or extremely satisfied with their general social support. This contrasts with a lack of disease-specific social support, a similar finding to asthma studies [20]. This emphasises the importance of separate assessment of general and disease-specific social supports and the development of disease-specific support systems as part of the comprehensive management of COPD. The usual group may have developed alternative coping strategies, unlike the cylinder groups, who may have "relied" on cylinder availability. Mastery plays a considerable role in attenuating acute healthcare utilisation however there was no difference between patient groups. The only statistically significant difference in HRQL was improvement in the CRQ emotion domain in the usual care group. The cylinder may have served as a constant reminder of their disease severity with a potential effect on mood.

Management options for severe COPD are often unsatisfactory, hence the ongoing interest and lingering expectations as to 
the role of SBOT. SBOT continues to be widely prescribed [1, $5,6]$, seemingly driven by expectations as opposed to evidence-based guidelines. The potential for a powerful placebo effect underscores the importance of randomised, controlled studies.

In conclusion, in a 6-month randomised, double-blind, placebo-controlled, parallel group study, availability of shortburst oxygen therapy to chronic obstructive pulmonary disease patients following discharge after an exacerbation was not associated with differences in health-related quality of life or acute healthcare utilisation. These results, in conjunction with recent results of acute studies of short-burst oxygen therapy, provide no support for the widespread use of this form of oxygen prescription. Scarce health resources would be better directed to proven modalities, such as pulmonary rehabilitation.

\section{ACKNOWLEDGEMENTS}

The authors acknowledge funding from the Auckland Medical Research Foundation Green Lane Hospital Research and Educational Fund, Auckland, New Zealand. The authors wish to thank E. Robinson for her additional biostatistical help.

\section{APPENDIX 1}

\section{Patient information for use of cylinder gas} Introduction

You have been supplied with a cylinder system which may contain oxygen or air.

Safety

For safety reasons you must assume that your cylinder may contain oxygen. When using oxygen the following points should be noted:

- It is important when using oxygen to avoid naked flame (cigarettes, open fires, gas cookers, gas heaters) as oxygen makes things burn faster.

- It is safe to use enclosed electric heaters, but care must be taken not to let the tubing touch the appliance.

- If electric blankets are used ensure that they have an annual safety check.

\section{No smoking}

There should be no smoking with oxygen in the house.

\section{Equipment}

Your equipment should contain:

- Cylinder

- Nasal prongs: The correct way of wearing nasal prongs is over the ears and under the chin with the prongs pointing backwards. Wash the nasal prongs in warm soapy water, rinse and dry by shaking well then run oxygen through the prongs for a minute or two. Keep the prongs in a plastic bag when not in use. New nasal prongs will be supplied as required to maintain comfort and hygiene.

\section{Use of cylinder}

- You have been prescribed symptomatic short-burst cylinder supply.

- Please feel comfortable to use the cylinder whenever you perceive a need.

- You may use the cylinder as often or as little as you feel is required, for as long or as short a period of time as you feel required.

- Please set the flow rate to $2 \mathrm{~L} \cdot \mathrm{min}^{-1}$ and use your nasal prongs as instructed.

- Please ensure that you maintain your diary, which contains important information regarding your symptoms and cylinder use.

- Please remember to turn off when not required.

\section{Renewing supplies}

Please note that your cylinder has a contents gauge which indicates when your cylinder needs replacing.

- Your gauge when full will read 20,000 psi.

- When the gauge reads approximately 5,000 psi, please phone [relevant telephone number], and a further delivery will be arranged.

- Your cylinder should last approximately 14 hours at $2 \mathrm{~L} \cdot \mathrm{min}^{-1}$.

Travel

When travelling with your cylinder, ensure that it is secure and that it will not roll around or fall. There is a requirement to display a sticker in your car window in case of accidents to alert the Emergency Services to the presence of oxygen. These stickers will be provided.

\section{REFERENCES}

1 Domiciliary oxygen therapy services: clinical guidelines and advice for prescribers. A report of the Royal College of Physicians. London, Royal College of Physicians, 1999.

2 Stevenson NJ, Calverley PMA. Effect of oxygen on recovery from maximal exercise in patients with chronic obstructive pulmonary disease. Thorax 2004; 59: 668-672.

3 Lewis CA, Eaton TE, Young P, Fergusson W, Kolbe J. Short-burst oxygen therapy is ineffective both before and after exercise in patients with severe COPD. Eur Respir J 2003; 22: 584-588.

4 Nandi K, Smith AA, Crawford A, et al. Oxygen supplementation before or after submaximal exercise in patients with chronic obstructive pulmonary disease. Thorax 2003; 58: 670-673.

5 Okubadejo AA, Paul EA, Wedzicha JA. Domiciliary oxygen cylinders: indications, prescription and usage. Respir Med 1994; 88: 777-785. 
6 UK Prescription Pricing Authority. Annual Report 20032004; 83.

7 The Burden of COPD in New Zealand. Wellington, The Asthma and Respiratory Foundation of New Zealand, 2003.

8 Connors AF Jr, Dawson NV, Thomas C, et al. Outcomes following acute exacerbation of severe chronic obstructive lung disease. The SUPPORT investigators (Study to Understand Prognoses and Preferences for Outcomes and Risks of Treatments). Am J Respir Crit Care Med 1996; 154: 959-967.

9 Dahl R, Lofdahl CG. The economic impact of COPD in North America and Europe; Analysis of the confronting COPD survey. Respir Med 2003; 97: Suppl. 3, S1-S14.

10 Eaton T, Grey C, Garrett JE. An evaluation of short-term oxygen therapy: the prescription of oxygen to patients with chronic lung disease hypoxic at discharge from hospital. Respir Med 2001; 95: 582-587.

11 Nocturnal Oxygen Therapy Trial Group. Continuous or nocturnal oxygen therapy in hypoxaemic chronic obstructive lung disease; a clinical trial. Ann Intern Med 1980; 93 : 391-398.

12 Medical Research Council Working Party. Long-term domiciliary oxygen therapy in chronic hypoxic cor pulmonale complicating chronic bronchitis and emphysema. Lancet 1981; 1: 681-686.

13 Eaton T, Garrett JE, Young P, et al. Ambulatory oxygen improves quality of life of COPD patients: a randomised controlled study. Eur Respir J 2002; 20: 306-312.

14 Curtis JR, Deyo RA, Hudson LD. Health-related quality of life among patients with chronic obstructive pulmonary disease. Thorax 1994; 49: 162-70.

15 Stewart AL, Greenfield RD, Hays RD, et al. Functional status and well-being of patients with chronic conditions. Results from the Medical Outcomes Study. JAMA 1989; 262: 907-913.

16 Spencer S, Calverley PMA, Sherwood Burge P, Jones PW, on behalf of the ISOLDE Study Group. Health status deterioration in patients with chronic obstructive pulmonary disease. Am J Respir Crit Care Med 2001; 163: 122-128.

17 Eaton T, Lewis C, Kennedy Y, Kolbe J, Garrett JE. Longterm oxygen therapy improves health-related quality of life in severe COPD patients. Respir Med 2004; 98: 285-293.
18 BTS Guidelines for the management of Chronic Obstructive Pulmonary Disease. Thorax 1997; 52: Suppl. 5, S5.

19 O'Reilly P, Thomas HE. Role of support networks in maintenance of improved cardiovascular health status. Soc Sci Med 1989; 28: 249-260.

20 Kolbe J, Vamos M, Elkind G, Garrett J. Differential influences on asthma knowledge and self-management behaviour in acute severe asthma. Chest 1996; 110: 1463-1468.

21 Young P, Dewse M, Fergusson W, Kolbe J. Respiratory rehabilitation in chronic obstructive pulmonary disease: predictors of non-adherence. Eur Respir J 1999; 13: 855-859.

22 Standardization of Spirometry, 1994 Update. American Thoracic Society. Am J Respir Crit Care Med 1995; 152: 1107-1136.

23 Quanjer PH, Tammeling GJ, Cotes JE, Pedersen OF, Peslin R, Yernault JC. Lung volumes and forced ventilatory flows. Report Working Party Standardisation of Lung Function Tests, European Community for Steel and Coal. Official Statement of the European Respiratory Society. Eur Respir J 1993; 16: S5-S40.

24 Guyatt GH, Berman LB, Townsend M, Pugsley SO, Chambers LW. A measure of quality of life for clinical trials in chronic lung disease. Thorax 1987; 42: 773-778.

25 Jaeschke R, Singer J, Guyatt GH. Measurement of health status: ascertaining the minimal clinically important difference. Control Clin Trials 1989; 10: 407-415.

26 Brazier JE, Harper R, Jones NMB, et al. Validating the SF-36 health survey questionnaire: new outcome measure for primary care. BMJ 1992; 305: 160-164.

27 Zigmond AS, Snaith RP. The Hospital Anxiety and Depression Scale. Acta Psychiatr Scand 1983; 67: 361-370.

28 Diggle PJ, Liang K-Y, Zeger SL, eds. Analysis of longitudinal data. Oxford, Clarendon Press, 1994.

29 Evans TW, Waterhouse JC, Carter A, Nicholl JF, Howard P. Short burst oxygen treatment for breathlessness in chronic obstructive disease. Thorax 1986; 41: 611-615.

30 Herland K, Akselsen J-P, Skjonsberg O, Bjermer L. How representative are clinical study patients with asthma or COPD for a larger "real life" population of patients with obstructive lung disease. Respir Med 2005; 99: 11-19. 